\title{
A FORMAÇÃO DA DOUTRINA DOS DIREITOS FUNDAMENTAIS '
}

\author{
Enrique Ricardo Lewandowski \\ Professor Titular do Departamento de Direito do Estado da \\ Faculdade de Direito da Universidade de São Paulo
}

Resumo:

Aula sobre a evolução histórica dos direitos fundamentais e sua proteção desde os primórdios da civilização ocidental aos nossos dias.

\begin{abstract}
:
Lecture about the historic evolution of the fundamental rights and their protection from the begining of the western civilization to our days.
\end{abstract}

Unitermos: Direitos fundamentais; direitos humanos; direitos civis e políticos; direitos econômicos, sociais e culturais.

1. Modelos Jurídicos

Os filósofos costumam dividir o real em mundo da natureza e mundo da cultura; no primeiro encontramos o dado e no segundo o construído. O físico, o químico e o biólogo trabalham com o dado, ao passo que o cientista social, o jurista em particular, lida com o construído.

O jurista, em verdade, transcende a esfera do mero ser, do Sein, para operar no campo do dever ser, ou seja, do Sollen. Ele, porém, não limita suas indagações ao plano do Sollen, pois não trabalha apenas com um conjunto de normas preceptivas, logicamente encadeadas, conforme queria Kelsen, mas opera com modelos jurídicos, que constituem, no dizer de Reale, uma síntese dialética resultante do embate entre certas exigências axiológicas e um dado complexo fático, travado no âmbito de determinada conjuntura histórica.

Para compreender os multifacetados modelos jurídicos correspondentes aos direitos fundamentais é preciso, portanto, levar em conta os fatos e os valores que

1. Transcrição editada da fita gravada da Prova de Erudição prestada pelo autor, em 22 de agosto de 2003, como um dos requisitos do concurso público de provas e títulos para o provimento do cargo de Professor Titular de Teoria Geral do Estado da Faculdade de Direito da Universidade de São Paulo. 
eles incorporaram ao longo de sua evolução. Daí porque muitos estudiosos têm falado em diferentes gerações de direitos, considerando as várias épocas históricas em que apareceram. E esse desenvolvimento ao longo de gerações faz com que os direitos humanos sejam ontologicamente distintos, especialmente no tocante à sua eficácia.

\section{Cultura Ocidental e Humanismo}

Não se pode olvidar que os direitos humanos, tal como nós os compreendemos atualmente, têm uma origem comum: são produto da civilização ocidental, cuja nota distintiva é o humanismo, que consiste, segundo Reale, em tomarse o homem como valor-fonte de todos os valores. Isso não ocorre necessariamente em outras culturas, onde distintos são os paradigmas dominantes. No Oriente, como se sabe, a ênfase da cultura dá-se no universal, no coletivo, no social, seja na religião, seja na política. Basta pensar-se, por exemplo, no nirvana budista, que corresponde, em suma, a um estado espiritual alcançado por meio da supressão do desejo e da consciência individual, isto é, à completa integração da pessoa na natureza circundante. Também o confucionismo, que dominou por mais de dois mil anos o sistema filosófico da China, a partir do século $V$ a.C., e influencia até hoje o modo de pensar chinês e de boa parte do mundo oriental, baseia as relações pessoais no interesse mais amplo da comunidade.

O humanismo ocidental funda-se basicamente na idéia da sacralidade essencial das pessoas e na crença de que existem determinadas regras transcendentais às quais súditos e governantes estariam indistintamente submetidos. Esses valores manifestaram-se de maneira constante, ainda que de forma difusa e inarticulada, ao longo de toda a evolução do pensamento ocidental, encontrando expressão nos escritos sagrados judaico-cristãos, nos clássicos greco-romanos, na jurisprudência latina e na teologia medieval.

\section{Herança Judaico-Cristã}

Logo no Genesis, lembra a Bíblia que o homem foi criado à imagem e semelhança de Deus. E, como conseqüência dessa identificação da criatura humana com a divindade, passou-se a entender que toda ofensa injustificada ao indivíduo constituía, por extensão, um agravo à própria divindade. A civilização ocidental herdou ainda dos hebreus dos tempos bíblicos, a par dessa sacralização da pessoa humana, um 
intenso respeito às leis divinas. Com efeito, toda a conduta do homem, no Antigo Testamento, era minuciosamente regulada por um complexo de normas reveladas que abrangiam desde os simples e diretos mandamentos do Decálogo de Moisés até as mais sofisticadas regras ritualísticas do Pentateuco.

O Antigo Testamento, bem entendido, resumia-se, antes de mais nada, a um conjunto de preceitos éticos ao qual estavam submetidos humildes e poderosos indistintamente. Esse sentido ético da religião judaica, fundado na igualdade entre os homens e no respeito à pessoa humana, foi integralmente absorvido pelo Cristianismo. Questionado em Jerusalém por um escriba sobre os princípios que norteavam seus ensinamentos, respondeu Jesus, com singeleza, que, dentre os mais importantes, figurava o seguinte: "Amarás o teu próximo como a ti mesmo"

A doutrina simples de Cristo foi mais tarde aperfeiçoada pelo Apóstolo Paulo, o qual, ao longo de sua jornada em direção à Roma, passando pelo mundo helênico, introduziu na filosofia cristã os ideais estóicos de cosmopolitismo e de fraternidade entre os homens.

\section{Clássicos Greco-Romanos}

Os ideais humanísticos da filosofia estóica greco-romana, que repousavam sobre a noção de lei natural e sobre o conceito de identidade essencial dos homens, em verdade, ultrapassaram os lindes da doutrina cristã, influenciando importante parcela do pensamento antigo, como também do medieval e do moderno. Para os estóicos, as leis vigentes nos diversos Estados não possuíam um valor intrínseco, porquanto a legitimidade destas dependia de sua correspondência com as leis naturais, eternas e imutáveis, que exerceriam a função de paradigmas a todo o direito positivo.

Zenon de Citium, fundador da escola, nesse sentido, afirmava que " $a$ le $i$ natural é uma lei divina, e tem, como tal, o poder de regular o justo e o injusto". Ao conceito de lei natural, comum a todos os homens, acrescentaram os estóicos a concepção de que todas as pessoas eram iguais ab origine. Epicteto, escravo liberto e um dos mais notáveis pensadores do estoicismo, assinalava com rclação ao tema que todos os homens provinham de um mesmo pai, Zeus, sendo, pois, frutos de uma semente comum.

Essa crença numa fraternidade entre os homens, bem como a convicção de que as pessoas eram basicamente iguais, estando submetidas às mesmas leis naturais, desaguou numa perspectiva cosmopolita do mundo, que impregnou definitivamente o modo de pensar ocidental. 


\section{Jurisprudência Latina}

O estoicismo, cultivado entre os latinos por Cícero e Sêneca, além de outros, influenciou consideravelmente o Direito Romano: jurisconsultos como Gaio, Ulpiano e Marciano aceitaram a existência de um direito natural, adotando-o como padrão de interpretação do direito positivo e como fundamento do direito das gentes.

$\mathrm{E}$, sob o influxo dos ideais estóicos, vários imperadores introduziram significativas modificações na legislação romana, abrandando o rigor e o elitismo dos antigos cânones patrícios. Augusto, por exemplo, concedeu às viúvas a tutela dos filhos, outorgando assim capacidade jurídica às mulheres; Nero baixou normas que protegiam os escravos contra a desumanidade de seus senhores; Antonino Pio concedeulhes o direito de buscar refúgio nos altares dos deuses; Marco Aurélio interditou as lutas de gladiadores.

A ética estóica sobreviveu aos tumultuados anos que se seguiram à destruição de Roma pelos povos bárbaros, preservada pela Jurisprudência e pela Patrística, constituindo o elo de ligação entre o pensamento antigo e o medieval.

\section{Teoria Política Medieval}

A idéia estóica de que os homens eram iguais e livres por natureza, assim como a crença de que a ordem natural deveria nortear a ordem social, representaram verdadeiros axiomas sobre os quais se assentavam a Teologia, a Jurisprudência e a Teoria Política medieval.

É preciso reparar, no entanto, que a concepção estóica de ordem natural, tanto dos gregos, quanto dos romanos, diferia consideravelmente daquela que vigorava na Idade Média. Para os estóicos, a ordem natural confundia-se com a realidade cósmica, divina porém impessoal, ao passo que, no conceito medieval, ela representava o resultado concreto da manifestação da vontade de uma deidade unipessoal, particularizada, responsável pela ordenação do universo.

Com fundamento nessa perspectiva, os teóricos medievais repudiaram o poder absoluto dos governantes, sustentando que toda a autoridade encontrava-se limitada pelas regras promanadas do ordenamento divino. Isso significava, basicamente, que a autoridade deveria ser exercida segundo as leis da justiça, leis essas invíoláveis e irrevogáveis, visto que constituíam expressões da ordem natural criada pelo Supremo Legislador. 
Para Santo Agostinho, um dos precursores dessa tese, o homem, além de membro da civitas terrena, ou civitas diaboli, como também a chamava, era igualmente cidadão da civitas Dei, localizava em outro mundo, e que se fazia representar na Terra pela comunidade de fiéis, reunida em torno da Igreja, cujos preceitos deveriam ser observados por todos.

Já São Tomás de Aquino sustentava, em sua Sunmia Theologica, que a submissão dos homens às autoridades seculares encontrava-se condicionada ao respeito às regras da Justiça e à promoção do bem comum por parte destas. Aduzia ainda o Doctor Angelicus que ninguém era obrigado a sujeitar-se a um governante usurpador ou injusto, assinalando que a sedição ou revolta contra um tirano constituía um ato perfeitamente legítimo.

\section{Iluminismo, Jusnaturalismo e Contratualismo}

Em que pese a importância política dos teóricos medievais, somente a partir das lutas desencadeadas contra o Absolutismo, entre os séculos XVII e XVIII, com base nos ideais iluministas, é que se exteriorizou com clareza a noção de que o homem possui certos direitos inalienáveis e imprescritíveis, decorrentes da própria natureza humana e existentes independentemente de qualquer ação estatal. E por isso passou-se a entender, desde então, que tais direitos não poderiam ser, em hipótese alguma, vulnerados pelo Estado ou por qualquer outra instituição ou pessoa.

O Iluminismo, mais do que uma determinada filosofia, constituiu uma nova cosmovisão desenvolvida a partir do colapso da civilização medieval, que pretendia “iluminar com a razão" o obscurantismo e os exageros provocados pelo excessivo apego à religião e à tradição.

A desagregação do mundo medieval deveu-se em grande parte ao Renascimento e à Reforma, que fizeram ruir a multissecular estruturação cristã da sociedade, fundada sobre uma ordem transcendental. O Renascimento, de um lado, ao promover uma volta aos valores da civilização clássica, pagã, provocou uma secularização da vida em todos os seus planos. A Reforma protestante, de outro lado, ao pretender a purificação do Cristianismo, advogando um retorno às suas origens, ocasionou um abalo no arcabouço ideológico que dava sustentação à organização social e política da Idade Média.

No plano intelectual, o Iluminismo repousava sobre dois pilares: o Racionalismo e o Empirismo, duas tendências intelectuais paralelas representadas pelo 
pensamento de Descartes, Leibniz, Bacon, Berkeley, Hume e outros, que abriram caminho para a emancipação da razão, a valorização do espírito crítico e a fé na ciência.

Com esse fundamento, o Iluminismo tomou como ponto de partida para as suas especulações o homem natural, ou seja, o homem antes de seu ingresso na vida social, dando origem ao Jusnaturalismo e ao Contratualismo, correntes de pensamento interligadas, que tiveram como arautos Grocius, Puffendorf, Hobbes, Locke, Montesquieu, Rousseau e outros. Os jusnaturalistas e os contratualistas advogavam, respectivamente, a tese segundo a qual existiriam direitos naturais, eternos e absolutos, demonstráveis pela razão, válidos para todos os homens em todos os tempos e lugares, e a de que a principal, senão a única, missão do Estado, criado por um pacto entre as pessoas, consistiria em assegurar a sua plena fruição.

Hobbes, por exemplo, em meados do século XVII, dizia que o Estado —identificado por ele com um monstro bíblico, o Leviatã, — foi criado pelos homens com a exclusiva tarefa de garantir a segurança, de maneira a superar a situação de "guerra de todos contra todos", que imperava na natureza, onde o "homem era o lobo do próprio homem". Já para Locke, que escreveu o Second Treatise on Civil Government (1689), o Estado foi estabelecido mediante um contrato, com o único objetivo de assegurar o direito à vida, à liberdade e à propriedade. Numa outra linha Rousseau, em seu $\mathrm{Du}$ Contrat Social, redigido quase um século depois (1768), enfatizava a igualdade de todos diante do pacto social.

Com essas características, o Jusnaturalismo e o Contratualismo espalharam-se por toda a Europa e também pela América, servindo de base doutrinária às declarações de direito do século XVIII, que vieram a lume na esteira das revoluções liberais-burguesas.

\section{Direitos Individuais}

Os primeiros diplomas que surgiram a partir das idéias jusnaturalistas e contratualistas assumiram o caráter de declarações porque se acreditava que os direitos dos indivíduos não constituíam uma criação do Estado, existindo antes do advento deste. Bastava, assim, para que fossem respeitados, arrolá-los solenemente num documento formal, depois de racionalmente deduzidos a partir da natureza humana. Ao Estado, portanto, ficava absolutamente vedado intrometer-se na esfera dos direitos do indivíduo listados nas declarações, incumbindo-lhe, ao contrário, zelar por sua observância e conservação. 
Dentre os dircitos constantes nas principais declarações figuravam com destaque o direito à vida, à liberdade, à igualdade, à segurança e à propriedade, bem como os direitos políticos e o direito de resistência à opressão. Esses direitos naturais passaram a ser conhecidos como direitos individuais ou, ainda, como direitos civis $e$ políticos. São os denominados direitos de primeira geração, consagrados, dentre outros documentos, na Declaração de Direitos do Bom Povo de Virgínia, de 1776, na Declaração de Independência dos Estados Unidos da América, também de 1776, na Declaração dos Direitos do Honem e do Cidadão francesa de 1789, e nas primeiras dez emendas à Constituição americana de 1787, promulgadas em 1789.

\section{Revolução Industrial e Direitos Sociais}

Com a Revolução Industrial dos séculos XVIII e XIX, que correspondeu a um salto tecnológico deflagrado pela aplicação da máquina a vapor aos processos produtivos, o indivíduo, embora protegido contra o arbítrio do Estado por diversos instrumentos legais, viu-se completamente desguarnecido em face dos efeitos perversos do novo sistema econômico.

As péssimas condições de vida dos trabalhadores do século XIX, tão bem retratadas por Dickens, desencadearam um surto de greves, agitações e rebeliões por toda a Europa. Dentre as sublevações populares, decorrentes das lutas operárias, destacam-se as revoluções na França e na Alemanha de 1848, a Comuna de Paris, de 1871 e, em especial, por seus desdobramentos, a Revolução Russa de 1917.

Essas rebeliões constituíram o caldo de cultura em que se desenvolveu o sindicalismo de Sorel, Pouget, Labriola e Panunzio, de cunho revolucionário, o tradeunionismo de Owen, de natureza reformista, o anarquismo de Proudhon, Bakunin c Kropotkin, o socialismo útopico de Saint-Simon, Fourier e Blanki, o socialismo científico de Marx e Engels, cujo Manifesto Comunista (1848), findava com a famosa conclamação: "Proletários de todo o mundo, uni-vos" Até mesmo a Igreja, que até então se mantivera eqüidistante das questões sociais, engajou-se na disputa, editando a Encíclica Rerum Novarum (1891), subscrita pelo Papa Leão XIII.

A crescente pressão das massas forçou o Estado a abandonar a posição de mero espectador passivo dos conflitos sociais, na qual havia sido colocado pelos ideólogos liberais, obrigando-o a atuar na busca de soluções para os problemas da comunidade. Renunciando à sua postura abstencionista, o Estado passou a adotar uma atitude positiva, conferindo ao indivíduo, enquanto membro da coletividade, os denominados direitos econômicos, sociais e culturais, de segunda geração. 
Na verdade, a Revolução Industrial, no plano fático, e o ideário socialista, na esfera intelectual, revelaram ao mundo um novo tipo de homem, o homem real, concreto, situado, longe daquele homem natural dos iluministas, titular de direitos eternos e imutáveis. O homem abstrato do passado, assim, cedeu lugar ao trabalhador do presente, que passou a ser o novo sujeito de direitos.

Modernamente, dentre os direitos econômicos e sociais destacam-se os seguintes: o direito ao trabalho, a um salário mínimo e a uma duração máxima para a jornada de trabalho; o amparo em caso de desemprego, doença, velhice, invalidez e morte; a proteção da mulher e do menor no trabalho; a aposentadoria; o acesso à educação e aos bens da cultura etc. Também o direito de formar sindicatos e o direito de greve inscrevem-se sob essa rubrica. Como documentos pioneiros nessa campo tem-se a Constituição Mexicana de 1917, a Declaração do Homem Trabalhador e Explorado soviética de 1918 e a Constituição de Weimar de 1919, que em seu artigo 49 estabelecia que "a propriedade obriga"

A partir daí, os direitos econômicos, sociais e culturais passaram a integrar as constituições, ao lado dos direitos civis e políticos, que já faziam parte das cartas magnas surgidas no século XIX, desde o advento das duas constituições paradigmáticas do final do século XVIII: a Constituição dos Estados Unidos de 1787, que incorporou os Ten Ammendments, de 1789, à guisa de Bill of Rights, e a da França de 1791, que adotou como preâmbulo a Declaração dos Diretos do Homem e do Cidadão de 1789.

\section{Direitos de Terceira e Quarta Geração}

O reconhecimento dos direitos econômicos, sociais e culturais, ao lado dos antigos direitos individuais, todavia, não esgotou a produção legislativa no campo dos direitos fundamentais. De fato, com a explosão demográfica, as guerras mundiais, as agressões ao meio ambiente, a competição econômica internacional, em suma, com a globalização dos problemas do homem, sobretudo a partir da segunda metade do século $\mathrm{XX}$, surgiu uma nova classe de direitos, que se convencionou chamar de direitos de solidariedade ou de fraternidade, ou seja, direitos de terceira geração.

Tais direitos sucedem no tempo os direitos resultantes das revoluções liberais do século XVIII e os direitos decorrentes das agitações operárias do século XIX. Dentre eles destacam-se o direito à paz, o direito à autodeterminação dos povos, o direito ao desenvolvimento, o direito à proteção do meio ambiente e do patrimônio comum da humanidade etc. Esses direitos desenvolveram-se, mais do que nos 
ordenamentos jurídicos internos dos Estados, sobretudo no plano do Direito Internacional.

Atualmente, já se fala em direitos de quarta geração, decorrentes de novas carências enfrentadas pelos seres humanos, especialmente em razão do avanço da tecnologia da informação e da bioengenharia. De fato, hoje busca-se proteção contra as manipulações genéticas, antevistas por Huxley em seu livro Admirável Mundo Novo (1930), as quais permitem criar clones humanos e de animais, e em tese até mesmo centauros, minotauros e sátiros, além de outros seres fantásticos, imaginados pela Mitologia Grega, ou contra a invasão da privacidade, a massificação e o totalitarismo, prenunciados por Orwell em sua obra 1984 (1948), ou ainda contra a anônima e tentacular burocracia estatal e privada, prevista por Kafka em seu romance $O$ Processo (1915).

\section{Internacionalização dos Direitos Humanos}

Em razão das atrocidades cometidas durante a Segunda Guerra Mundial, percebeu-se que não bastava proteger os direitos humanos nas constituições dos diferentes Estados para evitar a sua violação. Desencadeou-se um movimento para a formalização dos direitos fundamentais no plano internacional, cujo marco inicial foi a famosa Declaração Universal dos Direitos do Homem (1948), da Organização das Nações Unidas, aprovada pelo voto afirmativo dos representantes de 48 países.

A maciça votação a favor da Declaração Universal e o fato de não ter sido registrada nenhuma manifestação contrária à sua aprovação faz dela um dos raros documentos em torno dos quais existe alé hoje um consenso unânime. Apesar de constituir uma mera declaração, alguns especialistas emprestam-lhe um caráter vinculante, dado o seu elevado valor moral, enquanto outros consideram-na padrão de interpretação da Carta da ONU.

A partir de então, outros documentos vieram à lume importantes documentos no plano regional e internacional. Na Europa, surgiu a Convenção Européia para a Proteção dos Direitos do Homem e das Liberdades Fundamentais (1950) e a Carta Social Européia (1961). Na ONU, novamente, a Assembléia Geral aprovou o Pacto Internacional sobre Direitos Econômicos, Sociais e Culturais e o Pacto Internacional sobre Direitos Civis e Políticos (1966). E, no Continente Americano, vários documentos importantes foram assinados, com destaque para a Declaração Americana dos Direitos e Deveres do Homem e a Carta Interamericana de Direitos Sociais e a Convenção Americana de Direitos Humano (1948), bem como o Pacto de 
São José da Costa Rica (1969). Além disso, surgiram muitos outros documentos internacionais para a proteção de minorias, mulheres, crianças idosos etc, especificando em convenções vinculantes os direitos consignados na Declaração Universal.

\section{Eficácia dos Direitos Humanos}

Como repara Bobbio, o problema fundamental dos direitos do homem, nos dias que correm, já não é mais conhecê-los ou justificá-los, mas protegê-los eficazmente, sobretudo para evitar as rupturas periódicas, que impedem a sua fruição, estudadas por Lafer, com base nos ensaios de Arendt sobre a "banalização do mal”. e a recorrência dos totalitarismos.

Ocorre que os direitos humanos, são ontologicamente distintos, conforme a geração a que pertencem, sobretudo quanto à sua eficácia. Os direitos individuais, isto é, os direitos civis e políticos, institucionalizados há mais de trezentos anos, além de claramente exteriorizados, por meio de normas de eficácia plena e aplicabilidade imediata, encontram-se protegidos por uma série de garantias bem definidas, que pouco variam de um sistema jurídico para outro. De um modo geral, em que pesem essas diferenças, o indivíduo ofendido em seus direitos pode recorrer ao Judiciário, invocando um remédio jurídico-processual adequado que fará cessar a violação, com destaque, entre nós, para o habeas corpus e o mandado de segurança.

Os direitos econômicos, sociais e culturais, de elaboração mais recente em termos históricos, de seu turno, nem sempre podem ser exigidos através dos tribunais, não só porque não estão tão claramente detinnidos como os de primeira geração, como também porque dependem de uma ação positiva do Estado para se concretizarem. A amplitude do direito à saúde, à educação e à previdência, como observa Bobbio, além de variarem em função da orientação político-ideológica dos governantes, depende das condições econômicas de cada país em particular.

Grande parte desses direitos encontram expressão por meio de normas programáticas, cuja principal função é a apontar rumos à atuação dos governantes c evitar que ajam em sentido contrário ao que elas prescrevem. Por isso, apesar de constituírem verdadeiros direitos subjetivos, na acepção técnica da palavra, a sua cobrança é mais política do que estritamente jurídico-processual.

A proteção dos direitos de terceira geração faz-se ainda mais problemática, visto que eles constituem aquilo que se convencionou chamar de direitos difusos ou de titularidade coletiva. Com efeito, salvo no caso do direito ao meio 
ambiente, hoje bem ou mal protegido por ações e normas específicas no plano do ordenamento jurídico dos diferentes Estados, os demais direitos, intitulados de solidariedade ou de fraternidade, também só podem ser, como regra, defendidos eficazmente por ações políticas.

Essa situação se repete na esfera internacional, onde as denúncias a violações de direitos civis e políticos são prontamente investigados pelos órgãos internacionais, como as comissões e os tribunais de direitos humanos, que exigem a cessação da ilegalidade, estabelecendo, quando pertinente, a reparação dos danos. Por outro lado, a implementação paulatina dos direitos econômicos, sociais e culturais é controlada por meio do exame e discussão de relatórios periódicos encaminhados pelos Estados aos órgãos internacionais competentes, os quais, dæpois de apreciados, são objeto de recomendações aos remetentes.

A proteção dos direitos de terceira geração no plano internacional apresenta ainda maiores dificuldades, porquanto ela se coloca, ao menos por ora, num plano eminentemente retórico, em razão sobretudo da grande competição registrada entre os Estado:s, empresas e outras organizações.

É importante registrar, no entanto, que, embora desenvolvidos ao longo de várias gerações, não existe hicrarçuia entre os dircitos humanos em função dessa cronologia. Todos eles têm o mesmo valor e são indivisíveis, pois não pode se pode dissociar, por exemplo, o direito à vida e à liberdade, que são de primeira geração, do direito à uma vida e liberdade digna, que só se materializam por meio dos direitos de segunda e terceira geração. É que todos os direitos, como ensina Comparato, tem como fundamento, indistintamente, a dignidade substancial da pessoa humana. Por esse motivo, Bonavides prefere falar em dimensões de direitos aos invés de gerações de direitos.

\section{Estado Democrático de Direito}

Uma das mudanças institucionais mais importantes registradas no século passado, ainda pouco notadas e insuficientemente estudadas quanto ao seu potencial de transformação política e social foi, sem dúvida, a transmudação paulatina da democracia representativa para uma democracia participativa.

Como se sabe, desde as revoluções liberais burguesas e a partir da implantação do constitucionalismo moderno, a participação do povo no poder deu-sc no contexto da democracia representativa, que é aquela em que o povo participa do 
poder através de intermediários ou de representantes. Isso porque a democracia direta, que existiu com restrições na Grécia Clássica c ainda subsiste em alguns cantões suíços, por meio da landsgemeinde, não pode ser aplicada aos Estados contemporâneos, que se caracterizam pela complexidade de suas relações sociais.

Essa dificuldade, aliada aos defeitos da representação política tradicional, tornada frágil pela amplitude dos mandatos e pela irresponsabilidade dos mandatários, deu origem a alguns institutos que diminuem a distância entre os cidadãos e o poder. São eles o plebiscito, o referendo, a iniciativa e o veto popular, o recall e a participação em colegiados de todo o gênero etc.

Cumpre notar que a nova participação popular não ocorre, como se poderia imaginar, a partir do indivíduo, do cidadão isolado, ente privilegiado e até endeusado pelas instituições político-jurídicas do liberalismo. O final do século XX e o século XXI, certamente, entrarão para a História como épocas em que o indivíduo se eclipsa, surgindo em seu lugar as associações, protegidas constitucionalmente, multiplicando-se as chamadas organizações não-governamentais, no plano interno e internacional, para a defesa dos direitos humanos.

Na verdade, transita-se do Estado de Direito para o chamado Estado Democrático de Direito, que constitui um aprofundamento do Estado Social de Direito, maximizando a àbertura de suas instâncias decisórias para os cidadãos.

\section{Direitos Humanos e Justiça Social}

Em suma, apenas nos quadros do Estado Democrático de Direito é que os direitos fundamentais, em suas várias gerações ou dimensões, como quer Bonavides, podem ser adequadamente protegidos. Não é por outra razão que Dallari, de longa data, vem ensinando que os direitos humanos inscritos nas constituições e nos documentos internacionais só terão significação prática se sociedade estiver organizada de forma justa, garantindo a todos os cidadãos a igualdade de oportunidades e a possibilidade de participação nas decisões políticas.

Dado o atual panorama do mundo, porém, esse ideal parece ainda longe de concretizar-se. De fato, como lembra Bobbio, no campo dos direitos fundamentais, "a história humana, embora velha de milênios, quando comparada às enormes tarefas que estão diante de nós, talvez tenha apenas começado"

São Paulo, dezembro de 2003. 